\title{
Huge Biloma in a child with unusual presentation
}

\author{
Professor Samir Ibrahim Hasan AISaffar \\ Department of Surgery, College of Medicine , University of Mosul , Mosul , Iraq \\ Correspondence: samiralsaffar@yahoo.com
}

(Ann Coll Med Mosul 2021; 43 (1):76-80).

Received: $11^{\text {th }}$ Febr. 2021; Accepted: $11^{\text {th }}$ April 2021.

\section{ABSTRACT}

Background: The term "biloma" describes a well-demarcated, encapsulated or not, intra-abdominal (extrahepatic or intrahepatic) bile collection outside the biliary tree, secondary to iatrogenic, traumatic or spontaneous rupture of the biliary tree. The clinical symptoms of bilomas are usually nonspecific, ranging from no symptoms to abdominal pain, jaundice, and fever. There were only few cases of huge bilomas in the literature but no report of conincidental extrahepatic and intrahepatic biloma in the same patient.

Case report: We report herein a 12 years boy with huge biloma $(20 \mathrm{~cm}$ in vertical diameter) after blunt abdominal trauma, presented with unique clinical features of marked emaciation and diffuse abdominal distention. To our knowledge this is the largest biloma ever reported in paediatric age group and the first biloma with such unique clinical presentation, and the first case with both extrahepatic and intrahepatic bilomas in single setting.

Conclusion: Although biloma is rare condition but it needs to be considered in differential diagnosis of diffuse abdominal distension in patients following abdominal trauma or surgery.

Keywords: Bile Ducts, Extrahepatic , Intrahepatic, latrogenic Disease .

$$
\begin{aligned}
& \text { كيس مراري كبير لطقل بغرض سريزي غير متوقع } \\
& \text { الاستاذ سمير ابر اهيم حسن الصفار } \\
& \text { فرع الجر احة ، كلية الطب ، جامعة الموصل ، الموصل ، المبل ، العراق }
\end{aligned}
$$

الخلفية: يصف مصطلح "الكيس الصفر اوي" على انه تجمع محدد للمادة الصفر اوية ، مغلفة أو غير مغلفة ، داخل البطن (خارج

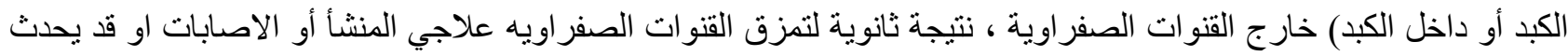

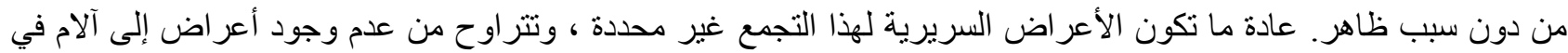

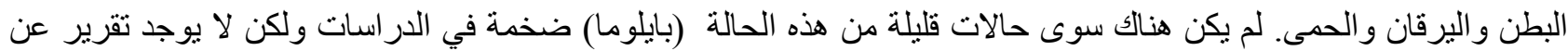

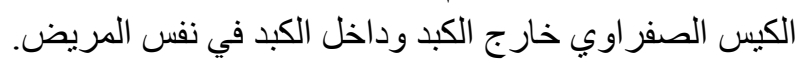

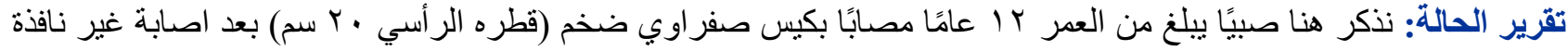

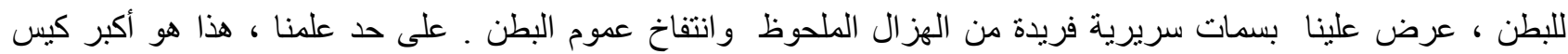

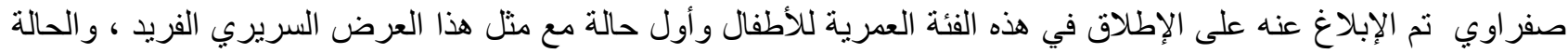

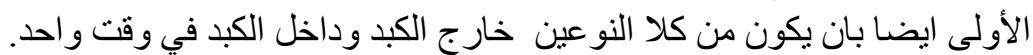

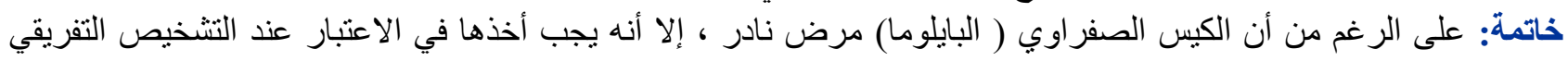
لانتفاخ عموم البطن في المرضى بعد صدمة مدن أو جراحة في البطن.

$$
\text { الكلمات المفتاحية: القنوات الصفر اوية ، خارج الكبد ، داخل الكبد ، علاجي المنشأ . }
$$




\section{CASE PRESENTATION}

A 12 years boy who was involved in a car accident, sustained blunt trauma to abdomen. Emergency laparotomy and splenectomy was performed in a local hospital.

The child passed an un-eventful postoperative course and discharged home after one week. One month later he started to complain of abdominal discomfort, anorexia, and wasting. The patient was neglected until referral to our tertiary hospital about 2 months later. He was presented complaining of diffuse abdominal distension and wasting. On examination, the patient was emaciated, pale, no jaundice, with sunken eyes.

The abdomen was hugely distended, tense, dull on percussion except on small area in the right side, [Figure 1].

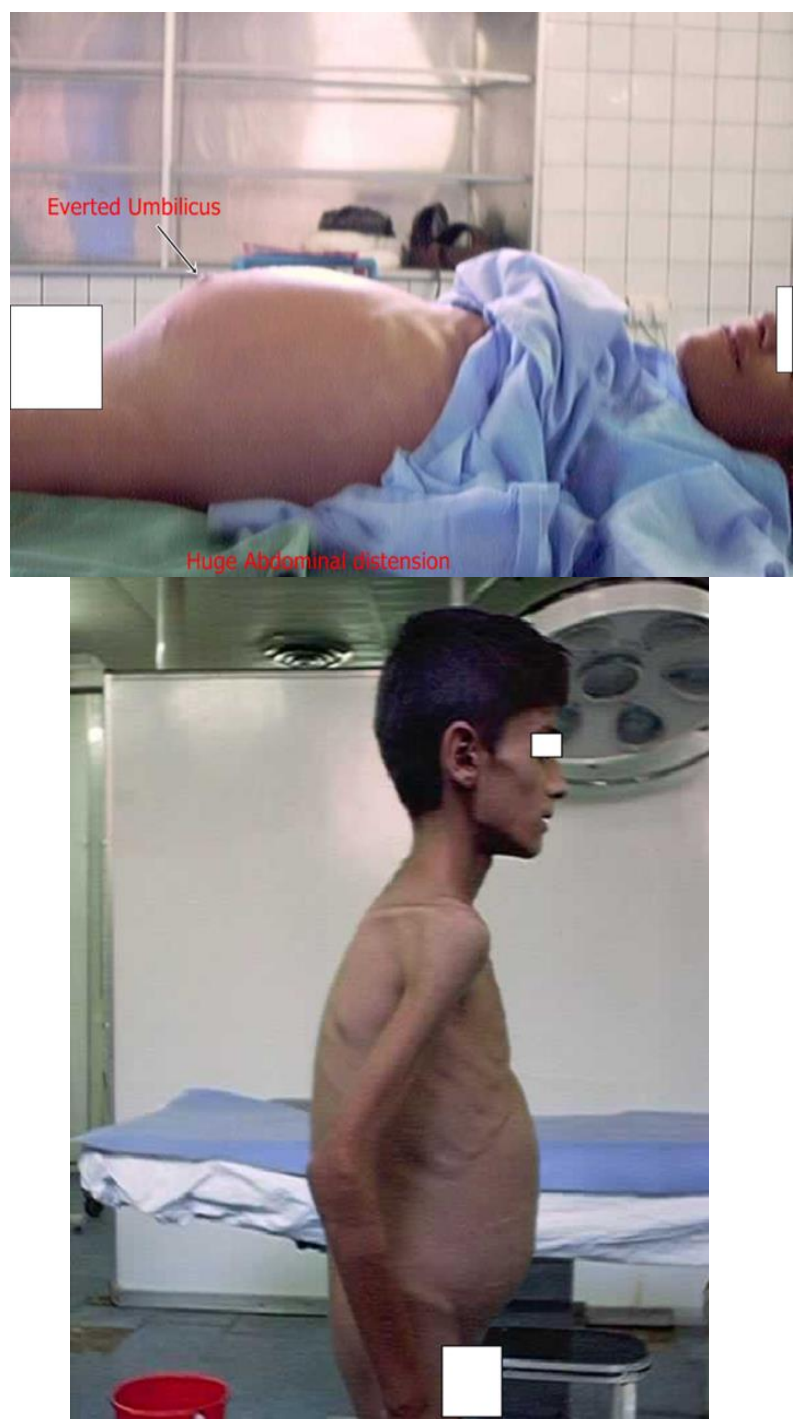

Figure 1: Huge abdominal distension with emaciation
There was a positive thrill and a negative shifting dullness. Bowel sounds were normal. Liver function tests were normal, bilirubin was $1 \mathrm{mg} / \mathrm{dl}$. Haemoglobin was $10 \mathrm{gm} / \mathrm{dl}$. Chest X-ray revealed abnormally elevated left dome of diaphragm, resulting from huge soft tissue density in the abdomen[Figure2]. Ultrasound examination revealed a huge cystic mass in the abdomen of undetermined origin.

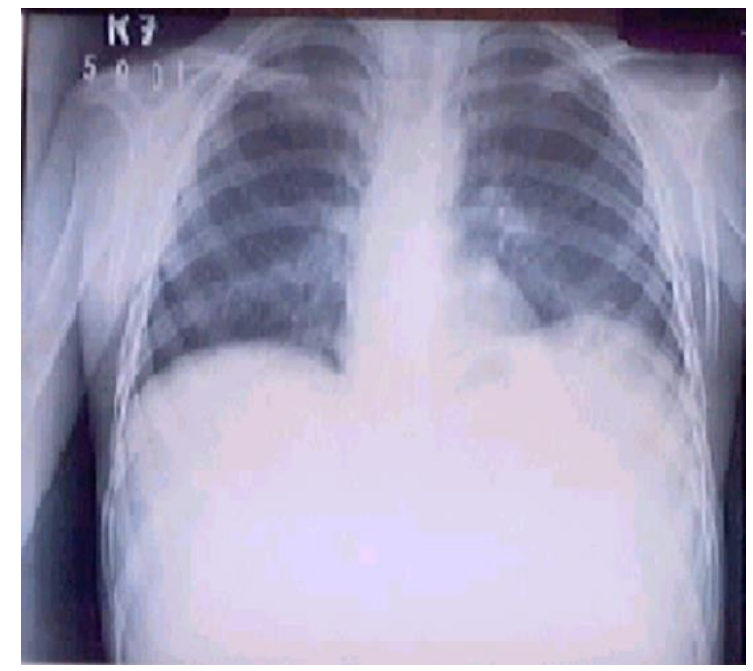

Figure2: CXR showed elevation of left dome of diaphgram

CT scan revealed a homogenous cystic mass extending from the left dome of diaphragm down to the pelvic area $(20 \mathrm{~cm}$ vertical diameter) [Figure 3 A \& B]. In addition, CT scan also showed two intrahepatic cystic collections.

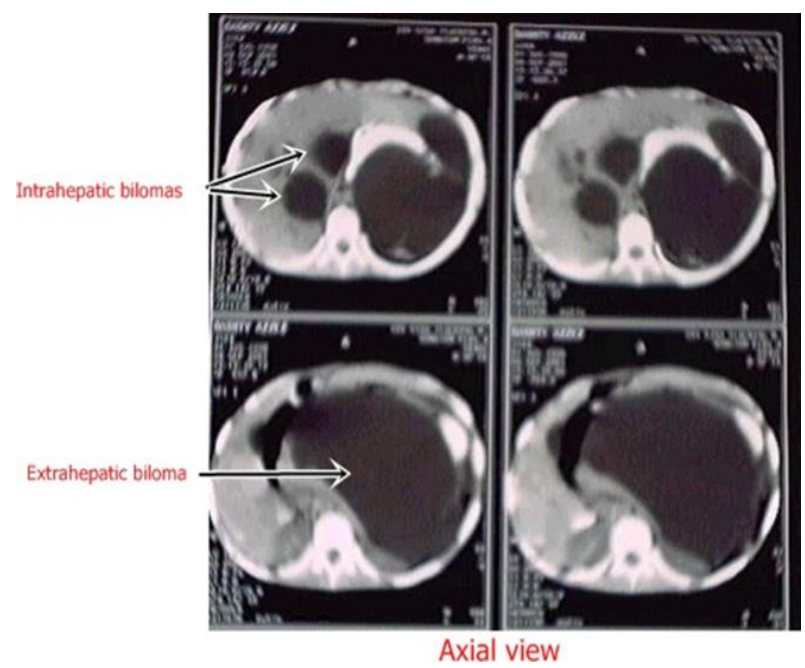

Figure 3 A: CT scan showing; A: the large extrahepatic biloma with the two intrahepatic biloma 


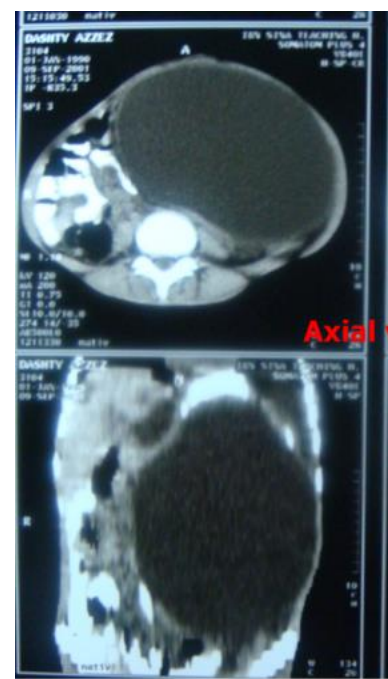

Saggital view

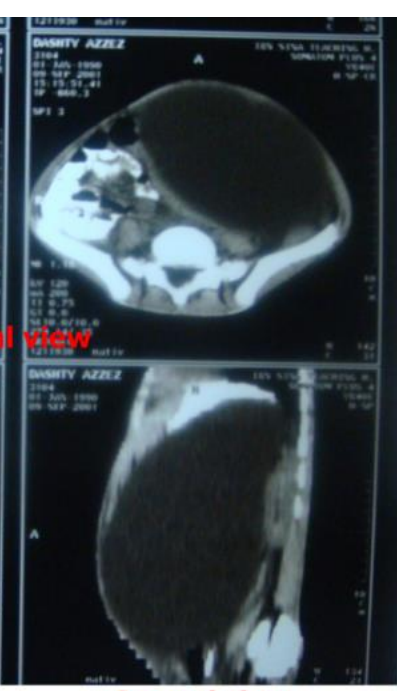

Coronal view

\section{B: CT scan showing the huge biloma (close view)}

Needle aspiration of the extrahepatic cystrevealed a greenish brownish fluid.

The differential diagnosis was either encysted bile collections or pseudocyst of pancreas, and a decision for surgical interference was taken.

Laparotomy was performed through the midline scar of the previous surgery. The peritoneum was opened and the cyst wall was found to be adherent to the anterior parietal peritoneum. The cyst was aspirated and then delivered outside the wound. The collection was found to be confined within the lesser sac stretching the transverse colon downwards. The cyst was opened through the gastrocoloic omentum and completely evacuated [Figure 4].

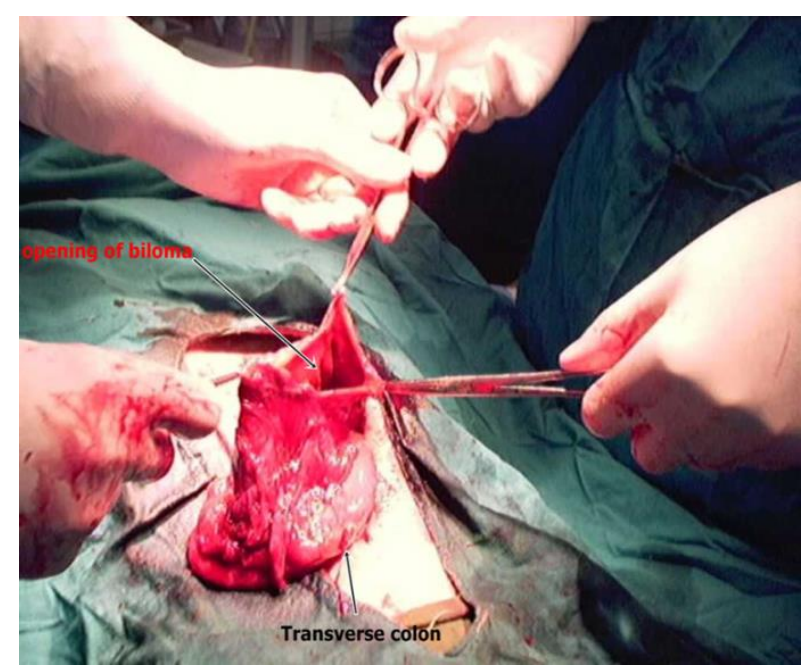

Figure 4: Intraoperative image of opened sac and its relation to transverse colon
A total of $4200 \mathrm{ml}$ of greenish brown, thick fluid with a lot of debris was evacuated, in addition to the fluid that was spilled over and soaked by packs. On exploring the cavity of the cyst, there was no apparent bile leakage from liver surface. After complete evacuation, external drainage by a tube drain was put in a dependent portion of the cavity.

Postoperatively the patient put on intravenous fluids, and parentral antibiotics. The postoperative period was uneventful; the drainage was 600,450 , 200 , and $120 \mathrm{mls}$ during the succeeding days. Oral intake was started at the second postoperative day and the patient discharged home at the $6^{\text {th }}$ postoperative day. At the $8^{\text {th }}$ postoperative day the drainage was only $100 \mathrm{ml}$, ultrasound examination revealed neither residual collection nor any intra hepatic collections, so the drainage tube removed.

The child was seen 2 months later in good condition with improvement in his nutritional status. Ultrasound examination of abdomen revealed no any pathology in the abdomen.

\section{DISCUSSION}

The term "biloma" describes a well-demarcated, encapsulated or not, intra-abdominal bile collection outside the biliary tree ${ }^{1-4}$. Whipple in 1898 was the first to describe a cystic swelling containing bile stained fluid following liver trauma ${ }^{5}$.

Gould and Patel in 1979 described an encapsulated bile collection in the right-upper abdominal quadrant following blunt abdominal trauma and called it a "biloma" ${ }^{6}$. Bilomas are either intrahepatic or extrahepatic ${ }^{7}$.

Bilomas are mainly caused by iatrogenic or traumatic injuries to biliary passages ${ }^{1,5,6}$. However there are few reports of spontaneous bilomas in the literature ${ }^{1,8}$. latrogenic injury to biliary passages following abdominal surgery is the most common cause of biloma ${ }^{8}$. Cholecystectomies whether open or laparoscopic are the main causes of biloma formation ${ }^{9,10}$.

Also bilomas were reported after liver transplantation and hepatic resections ${ }^{11}$. Blunt abdominal trauma was another important cause of biloma. Its pathogenesis is attributed to either direct disruption of extrahepatic bile ducts, or liver rupture with disruption of intrahepatic bile ducts, or secondary tissue necrosis with bile leakage ${ }^{6}$.

Post-traumatic bilomas have been rarely described in children and are still the subject of isolated case reports ${ }^{12}$. In our child the biloma was developed about 2 months after the trauma, and its pathogenesis can be explained as that of secondary tissue necrosis that lead to bile leakage. The leakage was minor and slowly accumulated over long time within the boundaries of lesser sac forming the huge extrahepatic biloma. 
Bilomas usually present with non specific clinical features like abdominal pain, nausea, anorexia, jaundice, fever and abdominal tenderness ${ }^{2,13}$.

However the history of recent surgery or trauma may highlight the suspicion of biloma. In our case, diffuse abdominal distension with marked emaciation was misleading as long as no such clinical presentation was ever reported before. In addition, the history of previous emergency splenectomy pointed to the suspicion of pseudocyst of pancreas as a sequel to iatrogenic injury to the tail of pancreas. For these reasons the definitive diagnosis was unexpected and only made after surgery. Even needle aspiration in our case failed to help in diagnosis because the collection was complicated by blood and the aspirate appeared greenish brown which is not the characteristric appearance of bile. However needle aspiration could be diagnostic in uncomplicated bilomas where the aspirate showing the characteristic appearance of bile ${ }^{14}$.

Ultrasonography is helpful in the diagnosis, where Biloma appear as an echo free with acoustic enhancement while CT scan in addition, it can define the cause and relations of bilomas with the adjacent structures more accurately ${ }^{3}$.

In our case the CT scan clearly identified the huge extrahepatic fluid collection, occupying the whole left side of abdomen. Interstingly another two intrahepatic cysts were seen by CT scan , appeared as hypodense lesions inside the liver. Such conincidence of both intrahepatic and extrahepatic bilomas in the same patient was not found in the literature. CT scan and ultrasonography cannot differentiate bile from other fluid collections; like hematoma, seroma, liver abscess, cysts, pseudocysts, and lymphocele and so cannot provide the definitive diagnosis ${ }^{15}$.

However cholescintigraphy by $99 \mathrm{mTc}$-PMT was useful for the accurate diagnosis, as it can demonstrate communications between the injured biliary systems and other spaces very clearly ${ }^{14}$.

Bilomas are liable for complications if left without treatment. Infection and rupture of bilomas into the peritoneal cavity are reported complications that may need aggressive surgical management 16

Only small asymptomatic ones that may resolve spontaneously can be followed without a need for intervension ${ }^{3}$. Percutaneous drainage was an effective form of therapy for extrahepatic biloma ${ }_{8}$ that often eliminated the need for surgical drainage 8

Percutaneous drainage of the intrahepatic biloma, with endoscopic retrograde cholangiopancreatography and papillotomy led to resolution of the problem in most cases ${ }^{17}$.
Surgery was performed in our patient mainly because of the extraordinary size of biloma thinking that percutaneous drainage may fail to completely sacrifice the problem. In addition the possibility of pseuodocyst of pancreas in our case was another reason for resorting to surgical decision. The surgery was successful in resolving the problem without any complications. However the resolution of the intrahepatic bilomas was unexpected and can't be explained as long as neither sphincterotomy nor aspiration was performed for the intrahepatic bilomas.

\section{CONFLICT OF INTEREST}

The author declare that there are no conflicts of interest regarding the publication of this manuscript .

\section{REFERENCES}

1.Carrillo Penso N, Hudson-JC. Biloma. G-E-N. 1991 Apr-Jun; 45(2): 140-4.

2. Hashemi SR, Ghaemian N, Abbaszadeh N, Marzbali, Reza A, Hasani M. Biloma due to blunt liver trauma. Casp J Intern Med.2010 Aut; 1(4):159-161.

3. Lee JH, Suh JI. A Case of Infected Biloma due to Spontaneous Intrahepatic Biliary Rupture. Korean J Intern Med. 2007;22(3):220-224. doi:10.3904/kjim.2007.22.3.220.

4. Mushtaque M, Farooq Mir M, Nazir P, Khan PS, Dadu V, A Dar L, A Dar R, A Khanday S. Spontaneous hepatic subcapsular biloma: Report of three cases with review of the literature. Turk J Gastroenterol. 2012 Jun;23(3):284-9

5. Whipple C. A case of traumatic rupture of liver: formation of cystic swelling containg bile stained fluid. Lancet. 1898; 1:719

6. Gould L, Patel A. Ultrasound detection of extrahepatic encapsulated bile: "biloma". AJR Am J Roentgenol 1979; 132(6): 1014-1015

7. Fritz HP, Polio J, Hewitt JK. Biloma secondary to hepatocellular carcinoma in an HIV-seropositive patient. Am-J-Gastroenterol. 1989 Dec; 84(12): 1560-3

8.Bas G, Okan I, Sahin M, Eryilmaz R, Isik A . Spontaneous biloma managed with endoscopic retrograde cholangiopancreatography and percutaneous drainage: a case report. Journal of Medical Case Reports 2011, 5:3. doi:10.1186/1752-1947-5-3.

9. Hassani KI, Benjelloun el B, Ousadden A, Mazaz $\mathrm{K}$, Taleb KA. A rare case of hepatic sub capsular biloma after open cholecystectomy: a case report. Cases J. 2009 Sep 15;2:7836. doi: 10.4076/1757-1626-2-7836. 
10. Brady AP; McGrath FP; Moote DJ; Malone DE. Post-laparoscopic cholecystectomy bilomaspreliminary experience. Clin-Radiol. 1992 Nov; 46(5): 333-6

11. Yo-ichi

Yamashita, Takayuki Hamatsu, Tatsuya Rikimaru, Shinji Tanaka, Ken Shirabe, Mitsuo Shimada, Keizo Sugimachi. Bile Leakage After Hepatic Resection. Ann Surg. 2001 January; 233(1): 45-50.

12. Cay A, Immamoglu M, Ahmetoglu A, Sarihan $\mathrm{H}$, Calapoglu AS. Bile duct injury complicated by biloma after blunt liver trauma in a child. Eur $\mathrm{J}$ Pediatr Surg 2006; 16: 205-8

13. Carroll BJ, Birth M, Phillips EH. Common bile duct injuries during laparoscopic cholecystectomy that result in litigation. Surg Endosc 1998;12: 310-314

14. Nakanishi $Y$, Kawa $S$, Shikaura $S$, Harima $K$, Sawada S, Tanaka Y, Kubota Y, Seki T. The usefulness of $99 \mathrm{mTc}$-PMT cholescintigraphy in the diagnosis of bile leakage or biloma. RinshoHoshasen. 1989 Aug; 34(8): 887-92.

15. Akhtar MA, Bandyopadhyay D, Montgomery HD, Mahomed A: Spontaneous idiopathic subcapsular biloma. J Hepatobiliary Pancreat Surg 2007, 14(6):579-581.

16. Makhija-M; Schultz-S; McManus-KT. Scintigraphy of bile leakage following cholecystectomy. Clin-Nucl-Med. 1985 Dec; 10(12): 848-50.

17. McLindon JP, England RE, Martin DF. Causes, clinical features and non-operative management of bile leaks. Eur Radiol. 1998; 8(9):1602-7. 